\title{
Call for uniform neuropsychological assessment after aneurysmal subarachnoid hemorrhage: Swiss recommendations
}

\author{
Antoinette E. Zweifel-Zehnder ${ }^{1} \cdot$ Martin N. Stienen $^{2} \cdot$ Christian Chicherio $^{3}$ • \\ Aline Studerus-Germann ${ }^{4}$ - Stefan Bläsi ${ }^{5} \cdot$ Stefania Rossi $^{6} \cdot$ Klemens Gutbrod $^{7}$. \\ Nicole Schmid ${ }^{8}$ • Valérie Beaud ${ }^{9}$. Christian Mondadori ${ }^{10}$ • Peter Brugger ${ }^{11}$. \\ Leonardo Sacco $^{6} \cdot$ Rene Müri $^{7}$ - Gerhard Hildebrandt ${ }^{12}$ • Jean-Yves Fournier ${ }^{12}$. \\ Emanuela Keller $^{13}$ • Luca Regli $^{13}$ • Javier Fandino ${ }^{14}$ • Luigi Mariani ${ }^{15}$. \\ Andreas Raabe ${ }^{16} \cdot$ Roy Thomas Daniel $^{17} \cdot$ Michael Reinert $^{18} \cdot$ Thomas Robert $^{18}$. \\ Bawarjan Schatlo $^{19}$ • Philippe Bijlenga ${ }^{2}$ - Karl Schaller ${ }^{2}$ Andreas U. Monsch ${ }^{5}$. \\ on behalf of the Swiss SOS study group
}

Received: 19 April 2015 / Accepted: 12 June 2015 /Published online: 16 July 2015

(C) Springer-Verlag Wien 2015

\begin{abstract}
Background In a high proportion of patients with favorable outcome after aneurysmal subarachnoid hemorrhage (aSAH), neuropsychological deficits, depression, anxiety,
\end{abstract}

Presentation at congresses: The recommendations have been submitted as an abstract to the annual meeting of the Swiss Society of Neurosurgery, as well as for the Vasospasm congress 2015.

Members and their affiliations are listed in the appendix

Antoinette E. Zweifel-Zehnder and Martin N. Stienen contributed equally to the manuscript and should thus be regarded as first authors

Electronic supplementary material The online version of this article (doi:10.1007/s00701-015-2480-y) contains supplementary material, which is available to authorized users.

Martin N. Stienen

mnstienen@gmail.com

1 Division of Neuropaediatrics, Development, and Rehabilitation, Department of Paediatrics, Inselspital Bern, Bern, Switzerland

2 Department of Neurosurgery and Faculty of Medicine, University Hospital Geneva, Geneva, Switzerland

3 Department of Neurology, Neuropsychology Unit, University Hospital Geneva, Geneva, Switzerland

4 Neuropsychology Unit, Department of Neurology, Kantonsspital St. Gallen, St. Gallen, Switzerland

5 Memory Clinic, University Center for Medicine of Aging, Felix Platter-Hospital, Basel, Switzerland

6 Department of Neurology, Neuropsychology Unit, Ospedale Regionale di Lugano, Lugano, Switzerland and fatigue are responsible for the inability to return to their regular premorbid life and pursue their professional careers. These problems often remain unrecognized, as no recommendations concerning a standardized compre-

\footnotetext{
7 Division of Cognitive and Restorative Neurology, Department of Neurology, Inselspital Bern, Bern, Switzerland

8 Neuropsychology Unit, Department of Neurology, Kantonsspital Aarau, Aarau, Switzerland

9 Neuropsychology Unit, Clinical Neurosciences Department, CHUV, Lausanne, Switzerland

10 Neurological Rehabilitation, Rehaklinik Bellikon, Bellikon, Switzerland

11 Neuropsychology Unit, Department of Neurology, University Hospital Zürich, Zürich, Switzerland

12 Department of Neurosurgery, Kantonsspital St. Gallen, St. Gallen, Switzerland

13 Department of Neurosurgery, University Hospital Zürich, Zürich, Switzerland

14 Department of Neurosurgery, Kantonsspital Aarau, Aarau, Switzerland
} 
hensive assessment have yet found entry into clinical routines.

Methods To establish a nationwide standard concerning a comprehensive assessment after aSAH, representatives of all neuropsychological and neurosurgical departments of those eight Swiss centers treating acute aSAH have agreed on a common protocol. In addition, a battery of questionnaires and neuropsychological tests was selected, optimally suited to the deficits found most prevalent in aSAH patients that was available in different languages and standardized.

Results We propose a baseline inpatient neuropsychological screening using the Montreal Cognitive Assessment (MoCA) between days 14 and 28 after aSAH. In an outpatient setting at 3 and 12 months after bleeding, we recommend a neuropsychological examination, testing all relevant domains including attention, speed of information processing, executive functions, verbal and visual learning/memory, language, visuoperceptual abilities, and premorbid intelligence. In addition, a detailed assessment capturing anxiety, depression, fatigue, symptoms of frontal lobe affection, and quality of life should be performed.

Conclusions This standardized neuropsychological assessment will lead to a more comprehensive assessment of the patient, facilitate the detection and subsequent treatment of previously unrecognized but relevant impairments, and help to determine the incidence, characteristics, modifiable risk factors, and the clinical course of these impairments after aSAH.

Keywords Aneurysmal subarachnoid hemorrhage . Neuropsychological assessment $\cdot$ Cognitive deficits . Psychosocial outcome · Test battery $\cdot$ Swiss standard . Standardized assessment

\section{Introduction}

Some decades ago, neurosurgeons, neuroradiologists, and neurointensive care physicians struggled to save the pure life of patients who had suffered from aneurysmal arachnoid hemorrhage (aSAH). Meanwhile, outcomes have improved due to

15 Department of Neurosurgery, University Hospital Basel, Basel, Switzerland

16 Department of Neurosurgery, Inselspital Bern, Bern, Switzerland

17 Department of Neurosurgery, CHUV, Lausanne, Switzerland

18 Department of Neurosurgery, Ospedale Regionale di Lugano, Lugano, Switzerland

19 Department of Neurosurgery, Georg-August University, University Medicine Göttingen, Göttingen, Germany less invasive aneurysm occlusion, newly introduced treatment options, and evidence-based managing guidelines [40]. However, up to a third of all aSAH patients still die as a consequence of severe brain damage in the prehospital phase or delayed brain injury in the subacute phase. On the other hand, however, a significant proportion of patients with low- or high-grade aSAH respond well to resuscitation and aggressive treatment and keep or regain their functional independence.

In clinical practice, neurovascular surgeons frequently encounter patients who survive the aSAH and seem to be functionally more or less independent, without any obvious neurological or cognitive deficits. Traditionally, these patients are assessed by means of rather imprecise neurological grading scales such as the Glasgow Outcome Scale (GOS) or the modified Rankin Scale (mRS). Still, many of these patients need weeks or months to regain their premorbid level, and resume work, if at all. Also, a majority of patients with an aSAH have to reduce their workload significantly, undergo professional retraining to a less demanding occupation, or have problems in relationships, family life, or leisure activities, indicating post-hemorrhagic difficulties due to e.g., cognitive deficits, depression, fatigue, or post-traumatic stress disorder [28, 47, $48,56,57,68]$. These facts clearly call for a more comprehensive assessment of those patients. Accordingly, many studies on this matter have revealed a strikingly high incidence of neuropsychological deficits (NPD) in the population of aSAH patients $[1,28]$. These are, according to a body of literature, determinants of functional independence, return to work, and health-related quality of life (HRQoL) after aSAH [1, 11, 29, $37,47,48,50,56,57]$. These findings have prompted us to reconsider the way aSAH patients are managed in Switzerland today.

\section{Objective}

Our aim is to establish a nationwide uniform, standardized, and validated neuropsychological assessment battery that is optimally suited to assess the most prevalent deficits in aSAH patients. This new set of tools must be available in different languages (i.e., German, French, Italian, and English). It is the goal of this recommendation to improve the management of aSAH patients in Switzerland by using a pragmatic approach. The specific aspects of these recommendations are (a) to offer guidelines concerning a comprehensive neuropsychological assessment for every aSAH patient, (b) to improve communication between neurosurgeons, neuropsychologists, rehabilitation units, and general practitioners, and (c) to expend health-care resources responsibly by implementing a standardized assessment to avoiding redundant examinations by multiple institutions. 


\section{Methods}

A workgroup consisting of representatives of the neurosurgical departments and neuropsychological units of all eight Swiss centers treating acute aSAH (in the following called "the panel"), namely the Kantonsspital Aarau (KSA), Universitätsspital Basel (USB), Inselspital Bern (ISB), Hôpitaux Universitaires de Genève (HUG), Centre Hospitalier Universitaire Vaudois (CHUV, Lausanne), Ente Ospedaliero Cantonale (EOC, Lugano), Kantonsspital St. Gallen (KSSG), and the Universitätsspital Zürich (USZ) that had joined their forces for the Swiss SOS study (www.swiss-sos.ch), were engaged in several face-to-face meetings and intense interpersonal communication between 09/2012 and 01/2015.

Based on a literature review on neuropsychological testing as well as HRQoL- and return to work outcomes after aSAH, available tests and questionnaires were collected and selected according to their sensitivity, validity, and utility in the population of aSAH patients. Only well-standardized tests and, from a more practical point of view, tests available in the three major languages of Switzerland (German, French, and Italian) were considered. Dissent was solved by personal discussion between the members.

The panel agreed on a standardized approach (Fig. 1) based on clear inclusion and exclusion criteria (Table 1) concerning the neuropsychological assessment of aSAH patients. Along with a comprehensive interview, the neuropsychological assessment battery had to fulfill the following criteria.

- Applicability in the clinical routine, i.e., considering both the reasonability to the aSAH patient, as well as the working capacity of the neuropsychologists

- Choice of tests that are sensitive, standardized, and valid including their availability in three official Swiss languages, i.e., German, French, and Italian as well as English - Inclusion of tests/questionnaires that depict the areas of impairment that are most commonly affected in aSAH patients according to the current literature [1, 28, 29, 47, $48,56,57,70,81-83$ ], namely (a) attention, (b) processing speed, (c) executive functions, (d) verbal and visual memory, (e) language, reading, writing, and calculation, (f) visuo-perceptual abilities, (g) premorbid intelligence, (h) depression, (i) anxiety, (j) fatigue, and (k) HRQoL

- Encumbers the health insurance system with reasonable expenses and helps to prevent unnecessary expenses by directing the patients into the right path as early as possible

Data of patients included in the Swiss SOS study is reported in this work. Written informed consent was obtained from all participants. Both local institutional review boards approved the study (Geneva: Autorisation générale Protocole $n^{\circ}$ 11-233R (NAC 11-085R); St. Gallen: EKSG 12/016/1B).

\section{Results}

Our interdisciplinary recommendations concerning the implementation of a standardized assessment including neuropsychological, functional, and HRQoL outcome into clinical routine have already been introduced at some of the centers in Switzerland and will soon be established on a nationwide basis. It is meant to serve the individual patient by detecting potential cognitive deficits as well as psychosocial impairment and rendering subsequent support and therapy possible. A second goal of this initiative is the acquisition of the detailed outcome data for scientific purposes within the framework of the Swiss SOS study [66]. We encourage other physicians to apply the same protocol in order to enable international comparison of standardized, detailed outcome measures and thereby significantly foster clinical research.

\section{Recommendation 1: Whom to test?}

In general, all aSAH patients deserve to receive a comprehensive assessment. However, in practice, certain factors need to be taken into consideration leading to the exclusion criteria outlined in Table 1. If a detailed neuropsychological testing at one point is not possible due to functional impairments that are a consequence of the aSAH itself, however, patients should not be generally excluded from further testing. It is well known that functional impairments often resolve over time, so that those patients should be re-evaluated later.

Thus, if deficits are too severe on the first encounter on day 14 in the subacute phase, cognitive screening should be postponed until day 28 (Fig. 1). Irrespective of the degree of impairment in the subacute phase, all aSAH patients should be scheduled for a thorough examination at month 3 and 12 posthemorrhage (see below). At these time points, a screening will help to determine if the comprehensive assessment can be carried out. Lastly, detailed neuropsychological testing of patients with a formal education of less than 7 years is problematic, as normative data is rarely available, and the results are difficult to interpret. Optionally, the remaining assessment tools (i.e., questionnaires and the Montreal Cognitive Assessment, MoCA) may be performed in those patients.

\section{Recommendation 2: When to test?}

A scheme providing an overview of the time axis of the assessments is presented in Fig. 1. In the acute phase of aSAH (0-14 days post-aSAH), a neuropsychological assessment is not reasonable or possible in a high percentage of patients, as they may have a reduced state of vigilance and/or attention span. Patients may still be comatose or have to undergo intensive treatment despite being awake, including e.g., strict bed rest and hypertensive treatment for cerebral vasospasm 


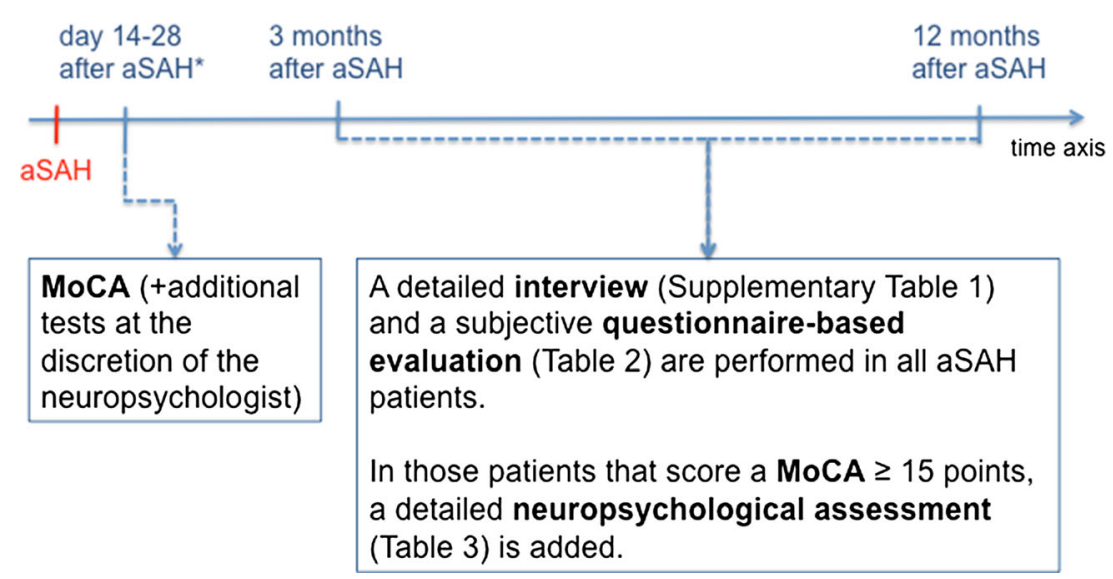

Fig. 1 Scheme of the Swiss standardized assessment after aSAH. MoCA Montreal Cognitive Assessment. * Testing should be performed on day 14 after aSAH, if possible. If not possible (e.g., patient still on respirator, comatose, not safe to perform the testing for medical reasons), the MoCA

(CVS), resulting in the inability of the patient to undergo testing at this time.

In the subacute phase (14-28 days post aSAH), we propose using the Montreal Cognitive Assessment (MoCA) as a standard [49], which is a short, simple-to-perform screening tool with a broad applicability and good validity for aSAH [81-83]. Additional tests can be added to the baseline evaluation at the discretion of the neuropsychologist to evaluate the need for an in- or outpatient (neuropsychological) rehabilitation program. We recommend administering the MoCA at day 14 post-aSAH, if possible. If the patient is unable to be tested at day 14 (e.g., comatose, intubated, etc.), the MoCA can be postponed day-by-day until day 28 post-aSAH. If the MoCA cannot be administered until day 28 , the patient will not be tested at baseline. Most of these patients present with unfavorable outcome at hospital discharge, so that the physician can usually decide for himself whether a transfer to an inpatient rehabilitation (potential for recovery) or nursing home (no potential for recovery) is necessary.

Table 1 Recommended criteria of whether or not to perform a detailed neuropsychological testing as part of a standardized outcome assessment

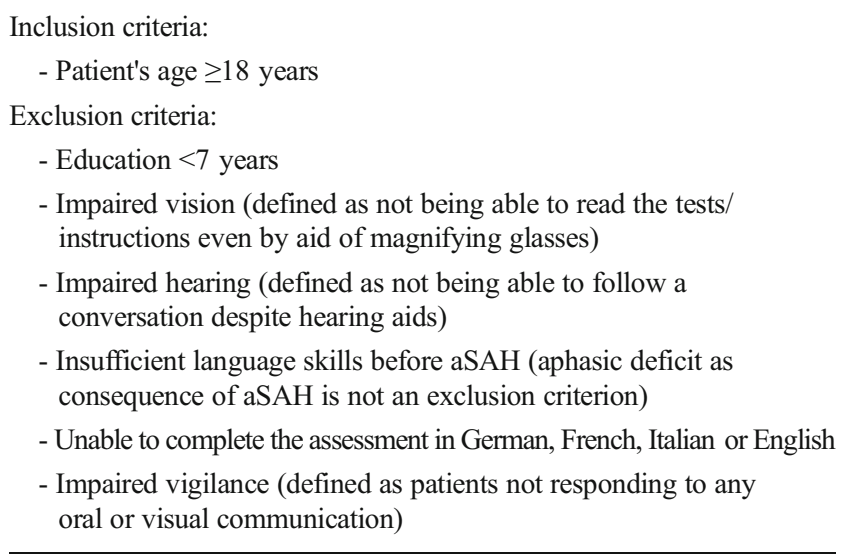

can be performed any day until day 28 after aSAH. If needed for the decision of whether or not the patient needs an inpatient rehabilitation program, the neuropsychologist can add specific tests at his discretion

Three months after aSAH, a standardized interview (Supplementary Table 1) and questionnaire-based evaluation (Table 2) should be performed in every patient. In addition, the MoCA should be repeated as a screening whether or not the complete neuropsychological test battery can be applied (the neuropsychologist should consider using parallel versions!). If the MoCA score is $\geq 15$ points, the test battery outlined in Table 3 should be used to complete the comprehensive patient evaluation. Patients not qualifying for the complete neuropsychological examination at 3 months should, however, be reassessed 12 months post-aSAH. If the full neuropsychological assessment is to be performed but patients are unable to do the whole examination due to fatigue for example, some subtests can be left out (at the discretion of the neuropsychologist) or the assessment can be dispensed to two or more examination dates. The examination at three months after aSAH is helpful to evaluate return to work, or the working capacity in those patients that have already restarted their professional lives.

Twelve months after aSAH, a second comprehensive outpatient neuropsychological assessment (using the same method as described for the 3-month examination, including the MoCA with a cut-off $\geq 15$ points) should be performed in every patient in order to estimate the presence and magnitude of cognitive deficits, anxiety, depression, fatigue, behavioral problems, and measure HRQoL. This visit is important in order to assess the natural course of symptoms and deficits or measure the efficacy of the applied therapy. In addition, this examination helps to determine if specific therapy has to be applied or continued, respectively.

\section{Recommendation 3: How to test?}

The following recommendations only apply to the follow-up examinations at 3 and 12 months post-aSAH, as in the subacute phase only the MoCA is performed (see above). The 
Table 2 Selection of questionnaires proposed at 3 and 12 months postaSAH to collect information on anxiety, depression, fatigue, symptoms of frontal lobe affection, and health-related quality of life.

- Hospital Anxiety and Depression Scale (HADS) [9, 56, 57, 76]

- Multidimensional Assessment of Fatigue (MAF) [37]

- Frontal Systems Behavior Scale (FrSBe) [41]

- Short-Form 12 (SF-12, including the Mental Component Scale (MCS) and Physical Component Scale (PCS), the subscales of Physical Functioning, Role-Physical, Bodily Pain, General Health, Vitality, Social Functioning, Role-Emotional, Mental Health) [34, 74]

- Euro-Qol (EQ5D) [62]

examination basically consists of three parts: (1) the interview, (2) the subjective questionnaire-based evaluation, and (3) the detailed neuropsychological assessment. It is important to note that part (1) and (2) should be applied to every patient, while not every patient qualifies for part (3). The complete examination comprising all three parts should take approximately $2.5 \mathrm{~h}$. Depending on the patients' condition, a split of the assessment should be considered.

\section{Part (1): Baseline interview, including working status and important life events}

The assessment should begin with a structured patient interview, where important patient characteristics are captured. These should include: age, gender, handedness (right/left/both), native language and language of examination, developmentalor learning disabilities (No/Yes, Type?), previous CNS comorbidities (e.g., head injuries, epilepsy, stroke, depression, anxiety), current medication, the consumption of cigarettes (number per day), alcohol (drinks per day), or further drugs. To evaluate the premorbid situation, the education in years and highest educational level (e.g., university degree, doctorate, apprenticeship, etc.) must be assessed. To estimate the impact of aSAH on the occupational career, both types of occupation before and after aSAH according to the International Standard Classification of Jobs (ISCO-88 COM) [75], the workload in percent (before and after aSAH), as well as the last day of work before- and the date of work resumption after aSAH should be recorded [50]. To cope with the social impact of the disease, we suggest inquiring about the family situations (e.g., marital status) before and after aSAH. Before any neuropsychological examination, the patient should be asked about self-pertained cognitive symptoms before and after aSAH and whether a neuropsychological examination had ever been performed before the aSAH. A sample of our structured interview sheet can be downloaded online from Supplementary Table 1.

Part (2): Questionnaires for anxiety, depression, fatigue, behavioral abnormalities, and HRQoL

Questionnaires outlined in Table 2, collecting information on anxiety, depression, fatigue, behavioral abnormalities as
Table 3 Recommended test battery for a comprehensive neuropsychological assessment 3 and 12 months after aneurysmal subarachnoid hemorrhage

\begin{tabular}{|c|c|}
\hline Domain & Test/subtest \\
\hline Cognitive screening & - MoCA [81-83] \\
\hline Attention & $\begin{array}{l}\text { - TAP } 2.3 \text {, using the subtests alertness; divided attention; Go/NoGo } \\
\text { (1 out of } 2) \text {; neglect (92 trials with switching letters) }[35,84] \\
\text { - Verbal }[12,80] \text { and visual [32] span - forward }\end{array}$ \\
\hline Executive functions & $\begin{array}{l}\text { - Color-Word Interference Test (Victoria version) }[7,14,20,59,60] \\
\text { - Verbal fluencies (semantic and phonemic) }[3,15,20,38,59] \\
\text { - Design fluency (five-points test) }[12,20,61] \\
\text { - Cognitive flexibility (TMT B) }[35,59,69] \\
\text { - Problem-solving (SLP) }[46]\end{array}$ \\
\hline Cognitive speed & - TMT A $[35,59,69]$ \\
\hline Memory & $\begin{array}{l}\text { - Verbal learning and memory (AVLGT) }[18,55,58] \\
\text { - Nonverbal memory (RO-CFT- delayed recall) }[1,2,20,54] \\
\text { - Verbal }[12,80] \text { and visual working memory }[32]\end{array}$ \\
\hline Visual-perceptual abilities & - RO-CFT - copy $[1,2,20,54]$ \\
\hline Language & $\begin{array}{l}\text { - Token test }[1,5,36,39] \\
\text { - Reading, writing, number processing and calculation } \\
\quad \text { (cursory examination) }\end{array}$ \\
\hline Premorbid intelligence & - Similarities $[7,12,80]$ \\
\hline Eye-hand coordination and motor speed & - Grooved Pegboard Test $[12,14,20,63]$ \\
\hline
\end{tabular}

AVLGT Auditiv-verbaler Lern- und Gedächtnistest (as adaptation of the Rey Auditory Verbal Learning Tests (RAVLT)), MoCA Montreal Cognitive Assessment, RO-CFT Rey-Osterrieth Complex Figure Test, SLP Standardized Link's Probe, TAP Computerized Test of Attentional Performance, TMT Trail Making Test 
probable symptoms of frontal lobe affection, and HRQoL are an essential part of the neuropsychological assessment.

\section{Part (3): Neuropsychological test battery}

The detailed neuropsychological testing is reserved for those patients that fulfill none of the exclusion criteria outlined in Table 1. After re-administering the MoCA at the beginning of the examination, one should refrain from further detailed neuropsychological testing of patients scoring $<15$ points (reason outlined above). All patients scoring $\geq 15$ points on the MoCA, however, qualify for a more detailed assessment using the test battery proposed in Table 3. The following domains are considered to be most important in aSAH patients and are thus covered by the test battery: attention, executive functions, processing speed, memory, visuoperceptual and constructional abilities, as well as language [1]. As mentioned, parts of the test battery may be omitted or divided and performed on two or more separate occasions if the patient is unable to perform the complete assessment in one session (e.g., limited span of attention, fatigue, aphasia). For the second examination (at 12 months), parallel test versions should be used whenever possible to prevent bias due to practice effects [64].

To conclude the assessment, observations made during the neuropsychological examination should be documented as proposed in Supplementary Table 2.

\section{Discussion}

We have undertaken efforts to develop and establish a nationwide standard that offers guidelines for a comprehensive assessment of aSAH patients including neuropsychological, psychosocial, and HRQoL implications of the disease. This proposed standard has been implemented in some of the Swiss neurovascular departments already, and is going to be adopted by the remaining departments in the near future. With this step, we hope to accurately diagnose the presence and magnitude of NPD, anxiety, depression, fatigue, and behavioral problems in the individual patient.

A detailed assessment identifying the characteristics and magnitude of the patient's individual deficits helps to initialize a specific therapy as early as possible and thereby maximize the chance of recovery. Detection of these impairments is crucial, as they are known to have a high incidence and impact on the subjects' well-being, the HRQoL and ability to work after aSAH [11, 53, 78]. Also, the early identification of deficits may help both the patient and his/her relatives to understand the reason for possible difficulties in the psychosocial, familiar, recreational and occupational re-integration, absorb future complications, and be helpful in estimating the patient's shortand long-term working capacity. As such, a recent study demonstrated that the neuropsychological outcome 12 months after aSAH could predict the ability to work even 10 years after the assessment [78]. Since aSAH patients are generally much younger than patients experiencing ischemic stroke for example, the significance of this estimation and its impact on our society becomes obvious. A detailed assessment is not possible in every patient, largely depending on his/her individual clinical condition. As such, we have introduced the MoCA as a screening tool (with the cut-off $\geq 15$ points) to decide whether or not the comprehensive test battery can be applied at 3 and 12 months post-aSAH. This approach both avoids bothering severely impaired patients and saves health care resources. There are no previous studies defining a similar cut-off, but it has been our experience in a pilot project on $n=61$ patients that a extensive assessment is not possible in patients scoring $<15$ points on the MoCA. In the subacute phase (14-28 days post-aSAH) $48.2 \%$ of patients scored $<15$ points in the Mo$\mathrm{CA}$, with the rate dropping to $25.8 \%$ and about $10 \%$ at 3 and 12 months post-aSAH. These numbers are in accordance with previous literature [81-83] and indicate that the battery can be applied to most of the surviving patients. Those that do not qualify for a more detailed assessment should be considered cognitively impaired and benefit from adequate support (ergotherapy, specialized cognitive training). However, further detailed testing of these patients using a 2.5-3 h face-to-face interview is impossible and little meaningful at this time.

Standardizing the way aSAH patients are assessed in a nationwide manner is a unique chance to study the incidence, evolution, and risk factors for psychosocial impairments. As such, we intend to record the results of the assessment in all patients that agree to participate in the prospective multicentre Swiss SOS study (www.swiss-sos.ch) [66]. By using the structures of this already well-established network, we can correlate psychosocial impairments to specific aspects of the disease and its treatment and profit from this massive gain of information not only from a scientific perspective, but also by means of an improved assistance of the individual patient. Identifying risk factors (especially modifiable risk factors) for neuropsychological outcome after aSAH is essential to facilitate their future prevention. As these are only beginning to be determined [70], there is a great need for further progress in clinical research. Only recently was it reported that characteristics of NPD after aSAH differ from those of other types of intracranial hemorrhage, as being more pronounced, but also more reversible [10]. This is good news, as impairment seems to be modifiable, again stressing the importance of its detection and subsequent therapy [70].

Until today, however, neuropsychological outcome after aSAH is not always assessed, and is especially underreported in scientific publications on aSAH. A recent analysis demonstrated the paradox between a high incidence of NPD on the 
one hand, and an extremely low frequency of their standardized assessment and scientific research in this area on the other hand [71]. In addition, the current assessment of NPD shows a great variability in published clinical series, and is often subject to profound selection bias. The need to obtain a general overview of neuropsychological outcome of aSAH patients remains largely unmet. Reasons for this are the missing neuropsychological infrastructure in some countries, and the challenge of such an endeavor with neurosurgeons and neuropsychologists of multiple centers having to cooperate.

Medical care in Switzerland is generally highly developed, and complex diseases such as aSAH are treated using the best standards of care. All aSAH patients surviving the initial hemorrhage and being admitted to a hospital in Switzerland as well as Liechtenstein and some neighboring regions of Italy, France, Austria, and Germany, are transferred to one of the above-mentioned centers for subsequent treatment. Owing to geographical and epidemiological features, and the complexity of the disease and its treatment, it has been decided in the context of the "Hochspezialisierte Medizin" (HSM; highly specialized medicine) discussion that aSAH should only be treated at the eight tertiary neurovascular centers listed above that cooperate tightly within the framework of the Swiss SOS study (members are listed in the author list as well as in the Appendix) [66]. Especially for a complex and relatively infrequent disease such as aSAH, standardized care, a focused medical supply and both quality assessment and control as well as scientific collaborations on a national level are warranted. In Switzerland, the local circumstances render the implementation of the proposed standard possible.

\section{Limitations}

The choice of tests and questionnaires that are depicted in Tables 2 and 3 constitute a compromise of experiences with aSAH patients, the availability of the tests in multiple languages, existence of normative data, alternate forms, as well as their reproducibility, cost-effectiveness, and meaningfulness for patient and scientific evaluation. Of note, besides the core test battery presented here, additional tests may be added to evaluate more specific deficits related to specific localization of the aSAH or its consequences (e.g., ruptured aneurysm of the anterior communicating artery with a frontal intracerebral hematoma-tests for social cognition; cerebral vasospasm of the right middle cerebral artery - mental rotation test). Still, the effect of fatigue in a significant percentage of patients should not be underestimated and the assessment kept as short as possible. From a scientific point of view, a further complete testing 60 months after aSAH would be of great interest to gain more insights into the clinical course of the psychosocial evolution of our patients. However, as this will be of little value to the clinical decision-making of the individual patient, the long-term testing cannot be included in this standard, which was primarily developed from a clinical point of view to improve patient care.

The fact that a pragmatic approach was chosen over a systematic evidence-based method (Delphi method) might be considered as a limitation. The agreement on this test battery was arrived at an internal discussion of the advantages and drawbacks of available tests, under the special consideration of previous literature. Personal experience of the panel members with this patient population supported the decision-making, which is why our proposed standard is not strictly scientific or evidence-based. Still, almost every test included in the battery proposed here has been demonstrated to be sensitive, valid, and utile in prior works on aSAH $[4,6,8-11,13,14,16$, 17, 19-31, 33-37, 42-45, 47, 48, 50-53, 55, 56, 59, 62, 64, $65,67,70-74,77-79,81-83]$. Establishing a standard is a big challenge for a single department and even more so for a whole nation with multiple language areas. By using a pragmatic approach though, we have been able to define a reasonable standard that might be adopted by further departments or countries in order enable international comparison of the results. Future works of this group will aim at reporting results using this battery that will help to estimate the burden of aSAH in an unselected nationwide patient population. Ongoing review of these results will help to optimize and possibly shorten this current standard in the future to enhance broad applicability, especially important for areas with fewer resources.

\section{Conclusions}

We have developed a nationwide standard for a comprehensive assessment of patients after aneurysmal subarachnoid hemorrhage that includes neuropsychological, psychosocial, and HRQoL-aspects of the disease. This standard will be implemented in all Swiss neurovascular departments treating acute aSAH and aims to accurately diagnose the presence and magnitude of neuropsychological deficits, as well as anxiety, depression, fatigue, and HRQoL in the individual patient in order to render subsequent treatment as early as possible. Scientific analysis of these detailed outcomes will help to understand the burden of this disease on patients and society, and enable fascinating insights into the pathophysiology of aSAH.

\section{Conflict of interest None.}

Informed patient consent Data of patients included in the Swiss SOS study are reported in this work. Written informed consent was obtained from all of these participants. Both local institutional review boards approved the study (Geneva: Autorisation générale Protocole n ${ }^{\circ} 11-233 R$ (NAC 11-085R); St.Gallen: EKSG 12/016/1B).

Financial disclosure There was no funding received for this work. 


\section{Appendix}

Further Swiss SOS contributors are listed below:

Ali-Reza Fathi, Serge Marbacher, Hassen Kerkeni, Jehuda Soleman, Daniel Coluccia, Carl Muroi, Hiroki Danura - Department of Neurosurgery, Kantonsspital Aarau, Switzerland

Jan-Karl Burkhardt, Oliver Bozinov - Department of Neurosurgery/Neurointensive Care Unit, University Hospital of Zurich, Zurich, Switzerland

David Bervini, Rodolfo Maduri, Marc Levivier - Department of Neurosurgery, Lausanne University Hospital, Lausanne, Switzerland

Andrea Ferrari, Martin Seule - Department of Neurosurgery, Kantonsspital St. Gallen, St. Gallen, Switzerland

Michel Röthlisberger, Daniel Zumofen, Raphael Guzman Department of Neurosurgery, Basel University Hospital, Basel, Switzerland

Daniel Schöni, Christian Fung, Jürgen Beck, Philippe Schucht - Department of Neurosurgery (2a) Department of Intensive Care Medicine, Inselspital, Bern, Switzerland

Daniele Valsecchi, Marta Arrighi, Dominque Emmanuelle Kuhlen - Department of Neurosurgery, Ospedale Regionale di Lugano, Lugano, Switzerland

Marco V. Corniola - Department of Neurosurgery, University Hospital Geneva, Geneva, Switzerland

Severin Früh - Neuropsychology Unit, Department of Neurology, Kantonsspital St. Gallen, St. Gallen, Switzerland

\section{References}

1. Al-Khindi T, Macdonald RL, Schweizer TA (2010) Cognitive and functional outcome after aneurysmal subarachnoid hemorrhage. Stroke 41:e519-536

2. Anderson SW, Todd MM, Hindman BJ, Clarke WR, Torner JC, Tranel D, Yoo B, Weeks J, Manzel KW, Samra S, Investigators I (2006) Effects of intraoperative hypothermia on neuropsychological outcomes after intracranial aneurysm surgery. Ann Neurol 60: $518-527$

3. Aschenbrenner A, Tucha O, Lange K (2000) RWT Regensburger Wortflüssigkeits-Test. Handanweisung, Hogrefe Verlag Göttingen

4. Barth M, Thome C, Schmiedek P, Weiss C, Kasuya H, Vajkoczy P (2009) Characterization of functional outcome and quality of life following subarachnoid hemorrhage in patients treated with and without nicardipine prolonged-release implants. J Neurosurg 110: 955-960

5. Becker F, Reinvang I (2007) Event-related potentials indicate bihemispherical changes in speech sound processing during aphasia rehabilitation. J Rehabil Med 39:658-661

6. Bellebaum C, Schafers L, Schoch B, Wanke I, Stolke D, Forsting M, Daum I (2004) Clipping versus coiling: neuropsychological follow-up after aneurysmal subarachnoid haemorrhage (SAH). J Clin Exp Neuropsychol 26:1081-1092

7. Bendel P, Koivisto T, Aikia M, Niskanen E, Kononen M, Hanninen T, Vanninen R (2010) Atrophic enlargement of CSF volume after subarachnoid hemorrhage: correlation with neuropsychological outcome. AJNR Am J Neuroradiol 31:370-376
8. Berry E, Jones RA, West CG, Brown JD (1997) Outcome of subarachnoid haemorrhage. An analysis of surgical variables, cognitive and emotional sequelae related to SPECT scanning. Br J Neurosurg 11:378-387

9. Boosman H, Passier PE, Visser-Meily JM, Rinkel GJ, Post MW (2010) Validation of the Stroke Specific Quality of Life scale in patients with aneurysmal subarachnoid haemorrhage. J Neurol Neurosurg Psychiatry 81:485-489

10. Brand C, Alber B, Fladung AK, Knauer K, Konig R, Oechsner A, Schneider IL, Tumani H, Widder B, Wirtz CR, Woischneck D, Kapapa T (2014) Cognitive performance following spontaneous subarachnoid haemorrhage versus other forms of intracranial haemorrhage. Br J Neurosurg 28:68-80

11. Carter BS, Buckley D, Ferraro R, Rordorf G, Ogilvy CS (2000) Factors associated with reintegration to normal living after subarachnoid hemorrhage. Neurosurgery 46:1326-1333, discussion 1333-1324

12. Chan A, Ho S, Poon WS (2002) Neuropsychological sequelae of patients treated with microsurgical clipping or endovascular embolization for anterior communicating artery aneurysm. Eur Neurol 47:37-44

13. Cheng H, Shi J, Zhou M (2006) Cognitive assessment in Chinese patients with aneurysmal subarachnoid hemorrhage. Behav Neurol 17:117-120

14. Crago EA, Thampatty BP, Sherwood PR, Kuo CW, Bender C, Balzer J, Horowitz M, Poloyac SM (2011) Cerebrospinal fluid 20-HETE is associated with delayed cerebral ischemia and poor outcomes after aneurysmal subarachnoid hemorrhage. Stroke 42: $1872-1877$

15. Escartin G, Junque C, Juncadella M, Gabarros A, de Miquel MA, Rubio F (2012) Decision-making impairment on the Iowa Gambling Task after endovascular coiling or neurosurgical clipping for ruptured anterior communicating artery aneurysm. Neuropsychology 26:172-180

16. Fontanella M, Perozzo P, Ursone R, Garbossa D, Bergui M (2003) Neuropsychological assessment after microsurgical clipping or endovascular treatment for anterior communicating artery aneurysm. Acta Neurochir (Wien) 145:867-872, discussion 872

17. Fukunaga A, Uchida K, Hashimoto J, Kawase T (1999) Neuropsychological evaluation and cerebral blood flow study of 30 patients with unruptured cerebral aneurysms before and after surgery. Surg Neurol 51:132-138, discussion 138-139

18. Gutbrod K, Balzer C (2011) Auditiv-verbaler Lern- und Gedächtnistest AVLGT. In: Balzer C, Berger J-M, Caprez G, Gonser A, Gutbrod K, Kelle M (eds) Materialien und Normwerte für die neuropsychologische Diagnostik. Verlag Normdaten Rheinfelden, pp 9-22

19. Hannerz H, Holbaek Pedersen B, Poulsen OM, Humle F, Andersen LL (2011) A nationwide prospective cohort study on return to gainful occupation after stroke in Denmark 1996-2006. BMJ Open 1, e000180

20. Haug T, Sorteberg A, Finset A, Lindegaard KF, Lundar T, Sorteberg W (2010) Cognitive functioning and health-related quality of life 1 year after aneurysmal subarachnoid hemorrhage in preoperative comatose patients (Hunt and Hess Grade V patients). Neurosurgery 66:475-484, discussion 484-475

21. Haug T, Sorteberg A, Sorteberg W, Lindegaard KF, Lundar T, Finset A (2009) Cognitive functioning and health related quality of life after rupture of an aneurysm on the anterior communicating artery versus middle cerebral artery. Br J Neurosurg 23:507-515

22. Haug T, Sorteberg A, Sorteberg W, Lindegaard KF, Lundar T, Finset A (2007) Cognitive outcome after aneurysmal subarachnoid hemorrhage: time course of recovery and relationship to clinical, radiological, and management parameters. Neurosurgery 60:649656, discussion 656-647 
23. Haug T, Sorteberg A, Sorteberg W, Lindegaard KF, Lundar T, Finset A (2009) Surgical repair of unruptured and ruptured middle cerebral artery aneurysms: impact on cognitive functioning and health-related quality of life. Neurosurgery $64: 412-420$, discussion 421-412

24. Hellawell DJ, Taylor R, Pentland B (1999) Persisting symptoms and carers' views of outcome after subarachnoid haemorrhage. Clin Rehabil 13:333-340

25. Hillis AE, Anderson N, Sampath P, Rigamonti D (2000) Cognitive impairments after surgical repair of ruptured and unruptured aneurysms. J Neurol Neurosurg Psychiatry 69:608-615

26. Hop JW, Rinkel GJ, Algra A, van Gijn J (2001) Changes in functional outcome and quality of life in patients and caregivers after aneurysmal subarachnoid hemorrhage. J Neurosurg 95:957-963

27. Hutter BO, Gilsbach JM (1995) Introspective capacities in patients with cognitive deficits after subarachnoid hemorrhage. J Clin Exp Neuropsychol 17:499-517

28. Hutter BO, Gilsbach JM (1993) Which neuropsychological deficits are hidden behind a good outcome (Glasgow = I) after aneurysmal subarachnoid hemorrhage? Neurosurgery 33:999-1005, discussion 1005-1006

29. Hutter BO, Gilsbach JM, Kreitschmann I (1995) Quality of life and cognitive deficits after subarachnoid haemorrhage. Br J Neurosurg 9:465-475

30. Hutter BO, Kreitschmann-Andermahr I, Gilsbach JM (2001) Health-related quality of life after aneurysmal subarachnoid hemorrhage: impacts of bleeding severity, computerized tomography findings, surgery, vasospasm, and neurological grade. J Neurosurg 94:241-251

31. Hutter BO, Kreitschmann-Andermahr I, Mayfrank L, Rohde V, Spetzger U, Gilsbach JM (1999) Functional outcome after aneurysmal subarachnoid hemorrhage. Acta Neurochir Suppl $72: 157-174$

32. Kessels RP, van Zandvoort MJ, Postma A, Kappelle LJ, de Haan EH (2000) The Corsi Block-Tapping Task: standardization and normative data. Appl Neuropsychol 7:252-258

33. Kim DH, Haney CL, Van Ginhoven G (2005) Utility of outcome measures after treatment for intracranial aneurysms: a prospective trial involving 520 patients. Stroke 36:792-796

34. King JT Jr, Horowitz MB, Kassam AB, Yonas H, Roberts MS (2005) The Short Form-12 and the measurement of health status in patients with cerebral aneurysms: performance, validity, and reliability. J Neurosurg 102:489-494

35. Krajewski K, Dombek S, Martens T, Koppen J, Westphal M, Regelsberger J (2014) Neuropsychological assessments in patients with aneurysmal subarachnoid hemorrhage, perimesencephalic $\mathrm{SAH}$, and incidental aneurysms. Neurosurg Rev 37:55-62

36. Kreiter KT, Copeland D, Bernardini GL, Bates JE, Peery S, Claassen J, Du YE, Stern Y, Connolly ES, Mayer SA (2002) Predictors of cognitive dysfunction after subarachnoid hemorrhage. Stroke 33:200-208

37. Kutlubaev MA, Barugh AJ, Mead GE (2012) Fatigue after subarachnoid haemorrhage: a systematic review. J Psychosom Res 72:305-310

38. Ladowski D, Qian W, Kapadia AN, Macdonald RL, Schweizer TA (2014) Effect of aneurysmal subarachnoid hemorrhage on word generation. Behav Neurol 2014:610868

39. Lammert A, Bode H, Hammes HP, Birck R, Fatar M, Zohsel K, Braun J, Schmieder K, Diepers M, Schubert GA, Barth M, Thome C, Seiz M (2011) Neuro-endocrine and neuropsychological outcome after aneurysmal subarachnoid hemorrhage (aSAH): a prospective cohort study. Exp Clin Endocrinol Diabetes 119:111-116

40. Lovelock CE, Rinkel GJ, Rothwell PM (2010) Time trends in outcome of subarachnoid hemorrhage: population-based study and systematic review. Neurology 74:1494-1501
41. Malloy P, Grace J (2005) A review of rating scales for measuring behavior change due to frontal systems damage. Cogn Behav Neurol 18:18-27

42. Manning L, Pierot L, Dufour A (2005) Anterior and non-anterior ruptured aneurysms: memory and frontal lobe function performance following coiling. Eur J Neurol 12:466-474

43. Martinaud O, Perin B, Gerardin E, Proust F, Bioux S, Gars DL, Hannequin D, Godefroy O (2009) Anatomy of executive deficit following ruptured anterior communicating artery aneurysm. Eur J Neurol 16:595-601

44. Mavaddat N, Sahakian BJ, Hutchinson PJ, Kirkpatrick PJ (1999) Cognition following subarachnoid hemorrhage from anterior communicating artery aneurysm: relation to timing of surgery. $\mathrm{J}$ Neurosurg 91:402-407

45. Mayer SA, Kreiter KT, Copeland D, Bernardini GL, Bates JE, Peery S, Claassen J, Du YE, Connolly ES Jr (2002) Global and domain-specific cognitive impairment and outcome after subarachnoid hemorrhage. Neurology 59:1750-1758

46. Metzler P (2000) Standardisierte Link'sche Probe zur Beurteilung exekutiver Funktionen (SLP). Manual. Swets Test Services Frankfurt a. M

47. Meyer B, Ringel F, Winter Y, Spottke A, Gharevi N, Dams J, Balzer-Geldsetzer M, Mueller IK, Klockgether T, Schramm J, Urbach H, Dodel R (2010) Health-related quality of life in patients with subarachnoid haemorrhage. Cerebrovasc Dis 30:423-431

48. Morris PG, Wilson JT, Dunn L (2004) Anxiety and depression after spontaneous subarachnoid hemorrhage. Neurosurgery 54:47-52, discussion 52-44

49. Nasreddine ZS, Phillips NA, Bedirian V, Charbonneau S, Whitehead V, Collin I, Cummings JL, Chertkow H (2005) The Montreal Cognitive Assessment, MoCA: a brief screening tool for mild cognitive impairment. J Am Geriatr Soc 53:695-699

50. Nishino A, Sakurai Y, Tsuji I, Arai H, Uenohara H, Suzuki S, Li JH (1999) Resumption of work after aneurysmal subarachnoid hemorrhage in middle-aged Japanese patients. J Neurosurg 90:59-64

51. Noble AJ, Baisch S, Mendelow AD, Allen L, Kane P, Schenk T (2008) Posttraumatic stress disorder explains reduced quality of life in subarachnoid hemorrhage patients in both the short and long term. Neurosurgery 63:1095-1104, discussion 1004-1095

52. Ohue S, Oka Y, Kumon Y, Ohta S, Sakaki S, Hatakeyama T, Shiraishi T, Takeda S, Ohnishi T (2003) Importance of neuropsychological evaluation after surgery in patients with unruptured cerebral aneurysms. Surg Neurol 59:269-275, discussion 275-266

53. Orbo M, Waterloo K, Egge A, Isaksen J, Ingebrigtsen T, Romner B (2008) Predictors for cognitive impairment one year after surgery for aneurysmal subarachnoid hemorrhage. J Neurol 255:17701776

54. Osterrieth PA (1944) Le test du copie d'une figure complexe: Contribution à l'étude de la perception et de la mémoire. Arch Psychol (Chicago) 30:206-356

55. Passier PE, Visser-Meily JM, Rinkel GJ, Lindeman E, Post MW (2011) Life satisfaction and return to work after aneurysmal subarachnoid hemorrhage. J Stroke Cerebrovasc Dis 20:324-329

56. Powell J, Kitchen N, Heslin J, Greenwood R (2004) Psychosocial outcomes at 18 months after good neurological recovery from aneurysmal subarachnoid haemorrhage. J Neurol Neurosurg Psychiatry 75:1119-1124

57. Powell J, Kitchen N, Heslin J, Greenwood R (2002) Psychosocial outcomes at three and nine months after good neurological recovery from aneurysmal subarachnoid haemorrhage: predictors and prognosis. J Neurol Neurosurg Psychiatry 72:772-781

58. Preiss M, Koblihova J, Netuka D, Bernardova L, Charvat F, Benes V (2012) Verbal memory capacity after treatment for ruptured intracranial aneurysm-the outcomes of three psychological tests: within a month, 1 year after and 5-7 years after treatment. Acta Neurochir (Wien) 154:417-422 
59. Proust F, Martinaud O, Gerardin E, Derrey S, Leveque S, Bioux S, Tollard E, Clavier E, Langlois O, Godefroy O, Hannequin D, Freger P (2009) Quality of life and brain damage after microsurgical clip occlusion or endovascular coil embolization for ruptured anterior communicating artery aneurysms: neuropsychological assessment. J Neurosurg 110:19-29

60. Regard M (1981) Cognitive rigidity and flexibility: a neuropsychological study. University of Victoria

61. Regard M, Strauss E, Knapp P (1982) Children's production on verbal and non-verbal fluency tasks. Percept Mot Skills 55:839844

62. Ronne-Engstrom E, Enblad P, Lundstrom E (2013) Health-related quality of life at median 12 months after aneurysmal subarachnoid hemorrhage, measured with EuroQoL-5D. Acta Neurochir (Wien) 155:587-593

63. Ruff RM, Parker SB (1993) Gender- and age-specific changes in motor speed and eye-hand coordination in adults: normative values for the Finger Tapping and Grooved Pegboard Tests. Percept Mot Skills 76:1219-1230

64. Santiago-Ramajo S, Katati MJ, Perez-Garcia M, Arjona-Moron V (2010) Evaluating the recovery of cognitive impairment in subarachnoid hemorrhage taking into consideration the practice effects. Neurosurgery 67:1497-1504, discussion 1504

65. Scharbrodt W, Stein M, Schreiber V, Boker DK, Oertel MF (2009) The prediction of long-term outcome after subarachnoid hemorrhage as measured by the Short Form-36 Health Survey. J Clin Neurosci 16:1409-1413

66. Schatlo B, Fung C, Fathi AR, Sailer M, Winkler K, Daniel RT, Bijlenga P, Ahlborn P, Seule M, Zumofen D, Reinert M, Woernle C, Stienen M, Levivier M, Hildebrandt G, Mariani L, Bernays R, Fandino J, Raabe A, Keller E, Schaller K (2012) Introducing a nationwide registry: the Swiss study on aneurysmal subarachnoid haemorrhage (Swiss SOS). Acta Neurochir (Wien) 154:21732178, discussion 2178

67. Seule MA, Stienen MN, Gautschi OP, Richter H, Desbiolles L, Leschka S, Hildebrandt G (2012) Surgical treatment of unruptured intracranial aneurysms in a low-volume hospital-outcome and review of literature. Clin Neurol Neurosurg 114:668-672

68. Sheldrick R, Tarrier N, Berry E, Kincey J (2006) Post-traumatic stress disorder and illness perceptions over time following myocardial infarction and subarachnoid haemorrhage. Br J Health Psychol 11:387-400

69. Spreen O, Strauss E (1998) A compendium of neuropsychological tests: administration, norms and commentary, 2nd edn. Oxford University Press, New York

70. Stienen MN, Smoll NR, Weisshaupt R, Fandino J, Hildebrandt G, Studerus-Germann A, Schatlo B (2014) Delayed Cerebral Ischemia Predicts Neurocognitive Impairment Following Aneurysmal Subarachnoid Hemorrhage. World Neurosurg 82(5):e599-605

71. Stienen MN, Weisshaupt R, Fandino J, Fung C, Keller E, Hildebrandt G, Studerus-Germann A, Muri R, Gutbrod K, Blasi S, Monsch AU, Brugger P, Mondadori C, Sailer M, Bijlenga P, Schaller K, Schatlo B, on behalf of the Swiss SOS study group
(2013) Current practice in neuropsychological outcome reporting after aneurysmal subarachnoid haemorrhage. Acta Neurochir (Wien)

72. Stienen MN, Weisshaupt R, Fandino J, Hildebrandt G, StuderusGermann A, Schatlo B (2015) Characteristics of patients without neuropsychological deficits following aneurysmal subarachnoid haemorrhage. Acta Neurochir Suppl 120:125-9. doi:10.1007/9783-319-04981-6 21

73. Tidswell P, Dias PS, Sagar HJ, Mayes AR, Battersby RD (1995) Cognitive outcome after aneurysm rupture: relationship to aneurysm site and perioperative complications. Neurology 45:875-882

74. Tjahjadi M, Heinen C, Konig R, Rickels E, Wirtz CR, Woischneck D, Kapapa T (2013) Health-related quality of life after spontaneous subarachnoid hemorrhage measured in a recent patient population. World Neurosurg 79:296-307

75. United Nations ILO (2004) International Standard Classification of Occupations, ISCO-88. http://www.ilo.org/public/english/bureau/ stat/isco/isco88/

76. van der Schaaf IC, Wermer MJ, Velthuis BK, Buskens E, Bossuyt PM, Rinkel GJ (2006) Psychosocial impact of finding small aneurysms that are left untreated in patients previously operated on for ruptured aneurysms. J Neurol Neurosurg Psychiatry 77:748-752

77. Vilkki J, Holst P, Ohman J, Servo A, Heiskanen O (1990) Social outcome related to cognitive performance and computed tomographic findings after surgery for a ruptured intracranial aneurysm. Neurosurgery 26:579-584, discussion 584-575

78. Vilkki J, Juvela S, Malmivaara K, Siironen J, Hernesniemi J (2012) Predictors of work status and quality of life 9-13 years after aneurysmal subarachnoid hemorrahage. Acta Neurochir (Wien) 154: 1437-1446

79. Vilkki JS, Juvela S, Siironen J, Ilvonen T, Varis J, Porras M (2004) Relationship of local infarctions to cognitive and psychosocial impairments after aneurysmal subarachnoid hemorrhage. Neurosurgery 55:790-802, discussion 802-793

80. Wechsler D (2008) Wechsler adult intelligence scale, 4th edn. Pearson, San Antonio

81. Wong GK, Lam S, Ngai K, Wong A, Mok V, Poon WS, Cognitive Dysfunction after Aneurysmal Subarachnoid Haemorrhage I (2012) Evaluation of cognitive impairment by the Montreal cognitive assessment in patients with aneurysmal subarachnoid haemorrhage: prevalence, risk factors and correlations with 3 month outcomes. J Neurol Neurosurg Psychiatry 83:1112-1117

82. Wong GK, Lam SW, Wong A, Lai M, Siu D, Poon WS, Mok V (2014) MoCA-assessed cognitive function and excellent outcome after aneurysmal subarachnoid hemorrhage at 1 year. Eur J Neurol 21:725-730

83. Wong GK, Lam SW, Wong A, Mok V, Siu D, Ngai K, Poon WS (2014) Early MoCA-assessed cognitive impairment after aneurysmal subarachnoid hemorrhage and relationship to 1-year functional outcome. Transl Stroke Res 5:286-291

84. Zimmermann P, Fimm B (2007) TAP Testbatterie zur Aufmerksamkeitsprüfung (Version 2.3) Psytest Herzogenrath 